\title{
Switching waves in asymmetric thyristor-like structures for incomplete gate turn off regime
}

\author{
Z. S. Gribnikov \\ Institute of Semiconductor Physics, NAS Ukraine, 45 prospekt Nauki, Kyiv, 252028, Ukraine
}

\author{
I. M. Gordion, and V. V. Mitin
}

Wayne State University, Detroit, MI 48202,USA zinovi@besm6.eng.wayne.edu

\begin{abstract}
A stationary wave of switching is considered in an infinite thyristor-like structure (TLS).This wave is initiated by the controlling gate current which differs from a certain equilibrium current $J_{g 0}(j)$ providing a neutrally equilibrium (translationally invariant) position of the transition layer between a blocked (OFF-) region and an open (ON-) region for a given current density $j$ in the ON-region. The dependence of the wave velocity $v(J, j)$ on the gate current $J_{g}$ and the current density $j$ is derived.We deal with structures in which the conductivity of gated base I is much higher than the conductivity of ungated base II.The injection level is considered low for base I and high for base II. It is shown that the velocity of the switching wave (i.e. the speed of transient processes in TLS) is determined mainly by parameters of base II. It is also demonstrated that a high speed of operation can be reached in structures with a moderately long base II (the length of the base should exceed 1-2 bipolar diffusion lengths) and a small lifetime of carriers in this base.
\end{abstract}

Keywords: switching waves, thyristor-like structure, transient processes, controlling gate current, injection level.

Paper received 22.06.98; revised manuscript received 29.07.98; accepted for publication 27.10.98.

\section{I.Introduction}

This paper is devoted to the control of the currentconducting region in a thyristor-like structure. Here, as well as before $[1,2]$ we refer to TLS as a certain $P^{+} n p N^{+}$ structure where two outer layers provide effective injection of their majority carriers into two inner layers (bases). One of the bases (base I) is gated. The gate transfers the controlling current into the base. This current squeezes the current-conducting region (the ON-region in fig. 1), and enlarges the OFF-region. The gated base is usually highly conducting in comparison with the second base (base II). In silicon controlled rectifiers (SCRs) [3], the gate current just turns the TLS on and off, while in lightemitting (LE) and lasing (L) thyristors the gate current can also control (or modulate) light emission $[4,5]$. That is why we are interested in characteristics of stationary control of the ON-region (the position of the layer between the ON- and OFF- regions, called the ON/OFF-junction) as well as the speed of the ON/OFF-junction in the TLS.

Our further consideration is based on the fact that the typical structures of LE thyristors $[6,7,8]$ differ greatly from the structures of SCRs. LE thyristors should not
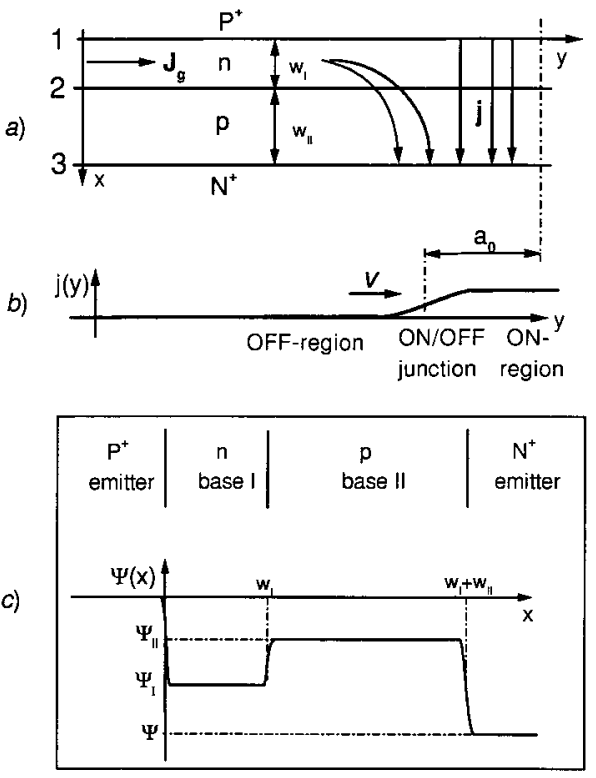

Fig. 1. a) Considered thyristor-like stucture (TLS) with b) the distributions of the current density $j(y)$ and c) the electrical potential $y(x)$ in it. 


\section{Z. S. Gribnikov et al.: Switching waves in asymmetric thyristor-like structures...}

usually resist high voltages, therefore the sum of the base widths, $w_{I}+w_{I I}$, is much smaller than the initial length of the ON-region, $2 a_{0}$, for most LE TLSs. Usually the value of $w_{I}+w_{I I}$ does not exceed $0.2-0.3 \mu \mathrm{m}$ while the initial length of the ON-region is rarely less than $10 \mu \mathrm{m}$. Detailed descriptions of the LE and L pnpn-diodes (having different names) with gated either $p$ - or $n$ - bases, are presented in [10-16]. For such structures the strong inequality $2 a_{0}>w_{I}+w_{I I}$ admits regimes with the width of the ON/ OFF-junction which is also much greater than $w_{I}+w_{I I}$. This means that the electrical potential changes quite smoothly along each base. The distribution of nonequilibrium carriers in the bases can be considered as nearly one-dimensional (1D) because the carrier concentrations change much slighter along $p n$-junction planes than in the perpendicular direction. Such distributions allow us to exploit a quasiadiabatic approach which was demonstrated earlier $[1,2,9]$. This approach assumes that the distribution of nonequilibrium carrier concentration can be represented as a function of $x$-coordinate and electric potentials of both bases, $U_{I}(y)$ and $U_{I I}(y)$. (Here $U_{I}$ is the voltage drop between the anode $P$ +-emitter) and base I, $U_{I I}$ is the voltage drop between the anode and base II). This approximation leads to a self-consistent system of two nonlinear differential equations for $U_{I, I}(y)$. This system can be solved numerically [2] or can be reduced to one nonlinear differential equation [1] under the condition

$\sigma_{I}>\sigma_{I I}$

where $\sigma_{I, I I}$ are the longitudinal (in-plane) conductivities of bases I,II.

Here we consider a structure where base I is doped much heavier than base II, so that inequality (1) is satisfied. We also assume low injection level in base I and high injection level in base II. For real asymmetric thyristors, the second assumption is more suitable than the assumption of low injection level in both bases, as was considered before [1, 2, 9]. We also keep assuming that carrier distributions in both bases are functions of the electric potentials, $U_{I, I I}(y)$, and of the voltage across the entire structure, $U$, which does not depend on $y$-coordinate. This representation for high injection level in base II is valid only if this base is not too long $\left(w_{I I} \leq(3-4) L\right.$, where $L$ is the bipolar diffusion length in base II), so that the voltage across the base can be neglected in comparison with the voltage across $p n$-junctions. Here we consider the problem of the steady-state position of the ON/OFFjunction as well as the nonstationary problem which can be described in the framework of the stationary switching wave approach [17].

Strictly speaking, the theory of the stationary wave can be applied only if the gate current and current density in the ON-region are time-independent. This condition requires infinitely large values of $a$ and $J_{a}$. However, we can use this approach to obtain an approximate solution of the nonstationary problem with comparatively slow changes of $J_{g}(t), a(t), j(t)$. These changes lead to a slow change of the velocity, $v(t)$, which should be constant for a strict stationary wave approach.

\section{Model and equations. Stationary theory}

The gate is attached to the $n$-base because the mobility of majority carriers (electrons) is much higher than that of holes for $A_{I I I} B_{V}$ materials we are interested in. We consider low injection level in this base, so that carrier distribution is determined by the linear equation of drift and diffusion of minority carriers. The boundary conditions for this equation are the following:

$p(x=0)=p_{0_{1}} e^{\psi_{I}}$,

$p\left(x=w_{I}-0\right)=p_{0_{2}} e^{2\left(\psi_{I}-\psi_{I I}\right)}$,

where $\psi_{I, I I}=\mathrm{e} U_{I, I I} /(k \mathrm{~T})$ are the dimensionless electrical potentials of bases I and II; $p_{0}$ is the equilibrium concentration of holes in base I at the $P+n$-junction (jct.1, $x=0$ ). To derive Eq.(3) we have to use the condition of conservation of quasi Fermi-levels in the inner np-junction (jct.2): $n p=$ const, i.e.

$p_{I}\left(w_{I}-0\right) \cdot n_{I}\left(w_{I}-0\right)=p_{I I}\left(w_{I}+0\right) \cdot n_{I I}\left(w_{I}+0\right)$

Because of high injection level in base II, we have

$p_{I I}\left(w_{I}+0\right) \approx n_{I I}\left(w_{I}+0\right)=N_{I} e^{-\psi_{0}+\psi_{I}-\psi_{I I}}$,

$p_{I}\left(w_{I}-0\right)=N_{I} e^{-2 \psi_{0}+2\left(\psi_{I}-\psi_{I I}\right)}$,

where $N_{I}$ is the donor concentration in base I at the inner $p n$-junction (jct.2), $n_{I}\left(w_{I}-0\right) e^{-2 \psi_{0}}=p_{0_{2}}$ is the effective hole concentration there (here $p_{02}$ is greater than the equilibrium concentration); and $\psi_{0}$ is the dimensionless value of equilibrium voltage across this $n p$-junction.

As the result of an approximate solution of the drift diffusion equation in base I, we obtain:

$$
\begin{aligned}
& j_{1}=j_{11} e^{\psi_{I}}-j_{12} e^{2\left(\psi_{I}-\psi_{I I}\right)}, \\
& j_{2}^{\prime}=j_{21} e^{\psi_{I}}-j_{22}^{\prime} e^{2\left(\psi_{I}-\psi_{I I}\right)}
\end{aligned}
$$

Since we consider that the values $\psi_{I},\left(\psi_{I}-\psi_{I L}\right)$ are high enough, we neglect 1 in comparison with $e^{\psi_{I}}, e^{(2)}\left(\psi_{I}-\psi_{I I}\right)$. In Eq.(7), $j_{1}$ is the current density through the emitter $P+n$-junction (jct.1). We assume that this junction - either homojunction or heterojunction - provides emission of the emitter majority carriers - holes - into base I. The current density through the inner $p n$-junction (jct.2) consists of two portions. The hole current density, $j_{2}^{\prime}$, is given by Eq.(8). The electron current density, $j_{2}^{\prime \prime}$, will be presented below. The values of $j_{11}, j_{12}, j_{21}, j_{22}^{\prime}$ can be calculated only for specified distributions of both donors and lifetimes of holes in base I.

For uniformly doped base I where the drift term can be neglected, we have:

$j_{11}=e p_{01} D_{I} \beta_{I} / \tanh z_{I}, \quad j_{22}^{\prime}=e p_{02} D_{I I} \beta_{I I} / \tanh z_{I I}$, 


\section{Z. S. Gribnikov et al.: Switching waves in asymmetric thyristor-like structures...}

$j_{21}=j_{11} \alpha_{I}, \quad j_{12}=j_{22}^{\prime} \tilde{\alpha}_{I}, \quad \alpha_{I}=\tilde{\alpha}_{I}=\left(\cosh z_{I}\right)^{-1}$

where $\beta_{I}$ is the inverse diffusion length of holes in base I: $\beta_{I}=\left(D_{I} \cdot \tau_{I}\right)^{-1 / 2} ; D_{I}$ is the coefficient of diffusion and $\tau_{I}$ is the lifetime of holes in base I; $z_{I}=\beta_{I} \cdot w_{I}$ is the dimensionless width of base I. We note that even for uniformly doped base I the concentrations $p_{0_{1}}$ and $p_{0_{2}}$ differ greatly because the latter is not a concentration of equilibrium holes.

Since we assume high injection level in base II, we can neglect the acceptor concentration in comparison with current carrier concentration and write the electron current in base II in the form:

$j_{n}=j \frac{b}{b+1}+D_{I I} \frac{d n}{d x}$

where $b=\mu_{n} / \mu_{p}$, and $\mu_{n, p}$ are the mobilities of electrons and holes in base II, and $D_{I I}=2 D_{n} D_{p} /\left(D_{n}+D_{p}\right)$ is the bipolar diffusion coefficient, $D_{n, p}$ are the diffusion coefficients of electrons and holes in base II, respectively. We assume that lifetime $\tau_{I I}$ in base II is constant. The continuity equation for electron current in base II has to be solved with the boundary conditions:

$p_{I I}\left(w_{I}+0\right) \approx n_{I I}\left(w_{I}+0\right)=n_{0_{2}} e^{\psi_{I}-\psi_{I I}}$

$p_{I I}\left(w_{I}+w_{I I}\right) \approx n_{I I}\left(w_{I}+w_{I I}\right)=n_{0_{3}} e^{\psi-\psi_{I I}}$,

where $n_{0,}$ and $n_{03}$ are the equilibrium concentrations in base II at junctions 2 and 3, respectively. These formulae are valid because low injection levels are considered in both base I and the $N+$-emitter. The expressions of current densities obtained from Eqs.(11), (12), (13) are written in the form:

$j_{2}^{\prime \prime}=j\left(w_{l}+0\right) \frac{b}{1+b}-j_{22}^{\prime \prime} e^{\psi_{I}-\psi_{I I}}+j_{23} e^{\psi-\psi_{I I}}$,

$j_{3}=j\left(w_{I I}\right) \frac{b}{1+b}-j_{32} e^{\psi_{I}-\psi_{I I}}+j_{33} e^{\psi-\psi_{I I}}$,

where

$j_{22}^{\prime \prime}=e n_{02} D_{I I} \beta_{I I} / \tanh z_{I I}, \quad j_{33}=e n_{03} D_{I I} \beta_{I I} / \tanh z_{I I}$,

$j_{32}=j_{22}^{\prime \prime} \alpha_{I I}, \quad j_{23}=j_{33} \alpha_{I I}, \quad \alpha_{I I}=\left(\cosh z_{I I}\right)^{-1} ;$

$\beta_{I I}=\left(D_{I I} \tau_{I I}\right)^{-1 / 2}$ and $z_{I I}=\beta_{I I} w_{I I}$ are the variables related to base II.

Here we apply one of the main assumptions of our consideration: the in-plane conductivity of base I is much greater than that of base II which depends on the electron concentration $n(x)$. This fact allows us to neglect the gate current which branches off into base II. So we assume

$j\left(w_{I}+0\right) \cong j\left(w_{2}\right)=j_{2} \cong j_{2}^{\prime}+j_{2}^{\prime \prime} \cong j_{3}$
From Eq. (18) we can obtain

$j_{2}=j_{3}=(1+b)\left[-j_{32} e^{\psi_{I}-\psi_{I I}}+j_{32} e^{\psi-\psi_{I I}}\right]$

$j_{2}=j_{3}=j_{2}^{\prime}+j_{2}^{\prime \prime}=(1+b) \times$

$\times\left[-j_{22}^{\prime} e^{2\left(\psi_{I}-\psi_{I I}\right)}+j_{21} e^{\psi_{I}}-j_{22}^{\prime \prime} e^{\psi_{I}-\psi_{I I}}+j_{23} e^{\psi-\psi_{I I}}\right]$

Using Eq.(19), (20) we can express the term $e^{\psi_{I}-\psi_{I I}}$ through the terms $e^{\psi-\psi_{I}}$ and $e^{\psi_{I}}$.

$e^{\psi I-\psi I I}=\sqrt{B_{0}^{2}+B_{1}^{2}}-B_{0}$,

where $B_{0}$ and $B_{1}$ depend on $e^{\psi_{I}}$ :

$B_{0}=j_{22}^{\prime \prime}\left(1-\alpha_{I I}\right)\left(1+e^{\psi-\psi_{I}}\right) /\left(2 j_{22}^{\prime}\right), \quad B_{1}^{2}=j_{21} e^{\psi_{I}} / j_{22}^{\prime}$.

As a result, the current continuity equation in base I can be written in the form:

$\frac{k T}{e} \sigma_{I} \frac{d^{2} \psi_{1}}{d y^{2}}=j_{11}\left(1-\alpha_{1} \tilde{\alpha}_{I}\right) e^{\psi_{I}}+\left(\sqrt{B_{0}^{2}+B_{1}^{2}}-B_{0}\right) \times$

$\times\left[j_{22}^{\prime \prime}\left(\alpha_{I I}(1+b)+\tilde{\alpha}_{I}\left(1-\alpha_{I I}\right)-\right.\right.$

$\left.-j_{33} e^{\psi-\psi_{I}}\left(1+b-\tilde{\alpha}_{I}\left(1-\alpha_{I I}\right)\right)\right]=R\left(\psi_{I}\right)$.

Generally, $\tilde{\alpha}_{I}=j_{12} / j_{22}^{\prime}$ can differ from $\alpha_{I}$.

\section{Homogeneous solution}

A homogeneous solution is valid when the gate current $J_{g}=0$, and all current densities through the $p n$-junctions are equal: $j_{1}=j_{2}=j_{3}=j$. Actually, the same equalities are valid for an inhomogeneous stationary solution in the depth of the ON-region. Thus we can treat the homogenous solution as a boundary condition for an inhomogeneous solution at $y \rightarrow \infty$. From the particular solution of Eq.(22) $\left(R\left(\psi_{I}=0\right)\right.$, we obtain:

$e^{\psi}=e^{\psi_{I}} \frac{(1+b) j_{32}+j / u}{(1+b) j_{33}}$,

$u=e^{\psi_{I}-\psi_{I I}}=\left(\frac{j_{11} e^{\psi_{I}}-j}{j_{12}}\right)^{1 / 2}$.

From Eq.(20), we can calculate the dependencies $e^{\psi_{I}}(j)$ and $e^{\psi}(j)$ (the latter being actually an expression for the voltage-current characteristic of the TLS):

$e^{\psi_{I}}=\frac{j}{j_{11}}+\tilde{\alpha}_{I} \frac{j_{22}^{\prime}}{j_{11}} r^{2}\left(\sqrt{1+\frac{j}{j_{c} r^{2}}}-1\right)^{2}$ 


\section{Z. S. Gribnikov et al.: Switching waves in asymmetric thyristor-like structures...}

$$
\begin{aligned}
& e^{\psi}=\frac{1}{(1+b) j_{11} j_{33}}\left[j+\tilde{\alpha}_{I} j_{22}^{\prime} r^{2}\left(\sqrt{1+\frac{j}{j_{c} r^{2}}}-1\right)^{2}\right] \times \\
& \times\left[\alpha_{I I} j_{22}^{\prime \prime}+\left(\sqrt{1+\frac{j}{j_{c} r^{2}}}+\right) j_{c} r\right]
\end{aligned}
$$

where $r=j_{22}^{\prime \prime} /\left(2 j_{22}^{\prime}\right) \cdot\left(1-\alpha_{I I}^{2}\right) /\left(1-\alpha_{I} \tilde{\alpha}_{I}\right)$ and

$$
j_{c}=j_{22}^{\prime}(1+b)\left(1-\alpha_{I} \tilde{\alpha}_{I}\right) /\left(\alpha_{I}(1+b)+\alpha_{I I}-1\right) .
$$

We consider more thoroughly two limiting cases: first, $j<<j r^{2}$, and second, $j>>j r^{2}$. For the first case, the dependencies $e^{\psi_{t}}(j)$ and $e^{\psi}(j)$ are linear (curves 1-3 in fig. 2 for the current range $\left.j /\left(j_{c} r^{2}\right)<<1\right)$ :

$$
e^{\psi_{I}}(j) \cong j / j_{I I},
$$

$$
e^{\psi}(j) \cong j \frac{j_{32}(1+b)+2 r j_{c}}{j_{I I}(1+b) j_{33}},
$$

Comparing Eq.(27) with Eq.(7) we note that for $j<<j r^{2}$, we can neglect the second term in Eq.(7). This means that this term $\left(e^{2\left(\psi_{I}-\psi_{I I}\right)}\right.$ instead of $e^{\psi_{I}-\psi_{I I}}$ for low injection levels in both bases) does not affect TLS's behavior. For this limiting case, the solution is very close to the solution for low injection levels in both bases (see,

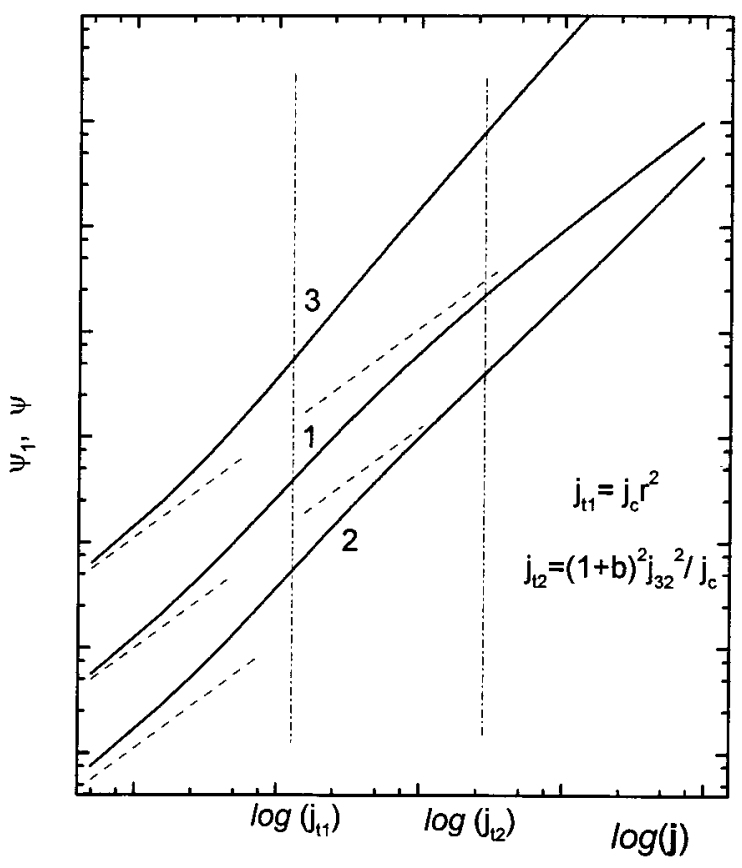

Fig. 2. The electrical potentials $\mathrm{y}, \mathrm{y}_{I}$ versus the current density $j$ : $1-y_{I}(j) ; 2-y(j)$ for $m<<1 ; 3-y(j)$ for $m>1$. for example, [1]).

For $j \gg j_{c} r^{2}$, the dependence $e^{\psi_{I}}(j)$ is still linear:

$e^{\psi_{I}}(j) \cong \frac{j}{j_{I I}}\left(1+\frac{j_{12}}{j_{c}}\right)$.

However, the proportionality coefficient here is larger than for $j<<j_{0} r^{2}$ (see fig. 2). To increase the current density further, we have to increase $U_{I}$ (or $e^{\psi_{t}}$ ) substantially because of a noticeable counteraction of the inner junction (jnc.2). Therefore we have to take into account the term, proportional to $e^{2\left(\psi_{I}-\psi_{I I}\right)}$. This dependence is strong if

$\frac{\tilde{\alpha}_{I}\left[\alpha_{I}(1+b)+\alpha_{I I}-1\right]}{(1+b)\left(1-\tilde{\alpha}_{I} \alpha_{I}\right)}>>1$.

Condition (30) is met in structures for which the forward and inverse transport factors in base I are large (both $\alpha_{I}$ and $\widetilde{\alpha}_{I}$ are close to 1 ), and the values of $b, \alpha_{I, I I}$ are far from the threshold values of the thyristor effect:

$\alpha_{I}(1+b)+\alpha_{I I}-1>0$

i.e. $\alpha_{I}(1+b)+\alpha_{I I}-1$ is not too close to 0 . We stress that the multiplier $(1+b)$ beside $\alpha_{I}$ which misses in the expression for low injection level in base II, corresponds to the transition into the $\mathrm{ON}$-state due to the increasing of injection level in base II.

For $j \gg>j_{c} r^{2}$ we get:

$e^{\psi}(j) \cong \frac{j \cdot j_{32}(1+b)+j^{3 / 2} j_{c}^{1 / 2}}{j_{11} j_{33}(1+b)}\left(1+\frac{j_{12}}{j_{c}}\right)$.

Expression (32) differs from expression (28) not only by the multiplier $\left(1+j_{12} / j_{c}\right)$ as in Eq.(29) but also by the term $j^{3 / 2} j_{c}^{1 / 2}$ instead of $2 r j_{c} j$ in the numerator. We can introduce the parameter

$m=\frac{2 r j_{c}}{j_{32}(1+b)}=\frac{1-\alpha_{I I}^{2}}{\alpha_{I I}\left[\alpha_{I}(1+b)+\alpha_{I I}-1\right]}$

to describe two different possible dependencies $e^{\psi}(j)$. For $m<<1$ in the current range $j \sim j_{c} r^{2}$, the value of $e^{\psi}$ becomes greater, but it is still a linear function with steeper slope up to the current density

$j \sim j_{32}^{2}(1+b)^{2} / j_{c}>j_{c} r^{2}$, where the curve becomes nonlinear: $e^{\psi}(j) \sim j^{3 / 2}$ (fig. 2). For $m>1$ the transition from a linear dependence, $e^{\psi}(j) \sim j$, to a nonlinear one, $e^{\psi}(j) \sim \mathrm{j}^{3 / 2}$, occurs in the current range $j \sim j_{c} r^{2}$.

Let us remind that this consideration implies low injection level in base I, so that the inequality

$p_{0_{1}} e^{\psi_{t}}(j)<<n_{D}(0)$

should be met (see Eq.(2)). Here $n_{D}$ is the donor concentration in base I at $p n$-junction 1. Let us discuss this condition for the simplest case of uniformly doped 


\section{Z. S. Gribnikov et al.: Switching waves in asymmetric thyristor-like structures...}

bases. For linear dependence $e^{\psi_{I}}(j)$, inequality (33) can be written in the form

$$
\frac{j}{j_{11}}<<\frac{n_{D}(0)}{p_{01}}=\frac{n_{D}^{2}}{n_{i}^{2}}
$$

On the other hand, the linear dependence $e^{\psi_{I}}(j)$ is valid for the current density

$$
\begin{aligned}
& \frac{j}{j_{11}}<<\frac{j_{c} r^{2}}{j_{11}}=\frac{n_{D}^{2}}{n_{i}^{2}} \times \\
& \times\left(\frac{1+b}{4} \cdot \frac{D_{I I} \tau_{I}}{D_{I} \tau_{I I}} \cdot \frac{\tanh ^{2} z_{I}}{\tanh ^{2} z_{I I}} \cdot \frac{1-\alpha_{I I}^{2}}{\alpha_{I}(1+b)+\alpha_{I I}-1}\right)
\end{aligned}
$$

The value of the multiplier in the parentheses of Eq.(34) can differ from 1 mainly due to a large difference of $\tau_{I}$ and $\tau_{I I}$. The condition $\tau_{I}<<\tau_{I I}$ can provide a regime of low injection level in base I up to high current density.

\section{Inhomogeneous stationary solution}

Now we are interested in Eq.(22) with a non-zero gate current, $J_{g}$, that squeezes the current-conducting region of a TLS. For

$$
B_{0}^{2} \gg B_{1}^{2}
$$

Eq. (22) has the form:

$$
\begin{aligned}
& \frac{k T}{e} \sigma_{I} \frac{d^{2} \chi}{d y^{2}}= \\
& =j_{11} \frac{\alpha_{I}(1+b)+\alpha_{I I}-1}{1-\alpha_{I I}} e^{\psi_{I}(\infty)} \frac{e^{x}\left(e^{x}-1\right)}{1+e^{x} / A}=R(\chi)
\end{aligned}
$$

where $\chi=\psi_{I}-\psi_{I}(\infty)<0, A=\left[1-\alpha_{I I}\left(1-\alpha_{I}(1+\mathrm{b})\right] /\left[\alpha_{I I}+\right.\right.$ $\left.+\alpha_{I}(1+b)-1\right]=e^{\psi_{I}(\infty)} / e^{\psi}=\left(j_{33}(1+b)\right) /\left(j_{33}(1+b) \alpha_{I I}+\right.$ $+2 j_{c} r$ ) (the second part of the expression is derived from Eqs.(27), (28) which are valid if $j<<j_{c} r^{2}$ ). For the stationary solution, the transition from the regime with low injection level in both bases to the regime with high injection level in base II and low injection level in base I (under condition (35)) results only in a new definition for the transport factor of base I, now being equal to $\alpha_{I}(1+b)$ instead of $\alpha$ for the low injection. This fact determines the choice of doping for the bases. It is clear that $n$-doped base I and $p$-doped base II structure, as we consider from the beginning, is preferable, because for most of the considered semiconductors $b>1$, and the condition of open state for the thyristor - inequality (31) - is satisfied for a wider range of $\alpha_{I I}$.

For $j<<j_{c} r^{2}$, inequality (35) can be modified to:

$$
j<<\frac{\left(j_{22}^{\prime \prime}\right)^{2}}{4 j_{22}^{\prime}} \cdot \frac{\alpha_{I}(1+b)^{2}\left(1-\alpha_{I I}^{2}\right)^{2}}{\left(\alpha_{I I}+\alpha_{I}(1+b)-1\right)^{2}}
$$

while the condition $j<<j_{c} r^{2}$ has the form:

$$
j<<\frac{\left(j_{22}^{\prime \prime}\right)^{2}}{4 j_{22}^{\prime}} \cdot \frac{(1+b)\left(1-\alpha_{I I}^{2}\right)^{2}}{\left(\alpha_{I I}+\alpha_{I}(1+b)-1\right)\left(1-\alpha_{I} \tilde{\alpha}_{I}\right)} .
$$

Inequalities (37) and (38) are not identical, but for most cases they differ only slightly. A detailed stationary solution for the distributions $\psi_{I}(y), j(y)$ for low injection level in both bases can be found in [1]. We emphasize, that eq.(36) differs from the analogous equation in [1] only by definitions of the parameters. From the solution of Eq.(36) we obtain that for infinite TLS there existsthe unique value of the gate current, $J_{g 0}$, which provides steady-state position of the ON/OFF-layer for a given current density in the depth of the ON-region:

$$
J_{g 0}=\sqrt{I_{1} \cdot j}
$$

The current density can be presented as $j=J_{a} /(2 a)$, where $J_{a}$ is the full current in the ON-region (in $\mathrm{A} / \mathrm{cm}$ ) and $2 a$ is an effective width of the ON-region (see fig. 1) where

$$
I_{1}=\frac{2 k \mathrm{~T}}{e} \sigma_{l} \frac{\alpha_{I I}+\alpha_{I}(1+b)-1}{1-\alpha_{I I}} A\left[(1+A) \ln \left(1+A^{-1}\right)-1\right] \text {. }
$$

\section{Stationary wave of switching}

We assume here that inertia of the transient processes in TLS is determined mainly by the drift-diffusion and recombination phenomena in quasineutral bases I and II; therefore we can neglect the charging processes in $p n$ junctions which are much faster. Therefore we have to solve two equations of continuity. The first of them is for holes in base I:

$\operatorname{div} \boldsymbol{j}_{p}=-p / \tau_{I}-\partial p / \partial t$

The second of them is the analogous nonstationary equation for electrons in base II. Here as well as in discussed above stationary problem, we neglect $\left(j_{p, n}\right)_{y}$ in comparison with $\left(j_{p, n}\right)_{x}$. Besides, we assume that the current density $\mathrm{j}$ changes slightly along $y$-axis over the lengths of the order of $w_{I, I I}$. To get the solution in the form of the stationary wave, we introduce new variables $x, y^{\prime}=y-v t$ instead of $x$, $y, t$; thus Eq.(41) is modified to

$\partial j_{p x} / \partial x=-p / \tau_{I}-v \partial p / \partial y$.

Equation (42) has to be solved with boundary conditions (2), (3) for $\psi_{I, I I}(y)$. For the small velocity and for uniformly doped base I (i.e. $j_{p x}=-D_{I} \partial p / \partial x$, we can write the approximate solution of Eq.(42) in the form:

$$
p(x, y) \cong p(0, y) \frac{\sinh \beta_{I}\left(w_{I}-x\right)}{\sinh \beta_{I} w_{I}}+p\left(w_{I}, y\right) \frac{\sinh \beta_{I} x}{\sinh \beta_{I} w_{I}}+
$$




\section{Z. S. Gribnikov et al.: Switching waves in asymmetric thyristor-like structures...}

$+\frac{v}{2 D_{I} \beta_{I}} \frac{\partial p(0, y)}{\partial y}\left[\left(w_{I}-x\right) \frac{\cosh \beta_{I}\left(w_{I}-x\right)}{\sinh \beta_{I} w_{I}}-\right.$

$\left.-w_{I} \frac{\cosh \beta_{I} w_{I} \cdot \sinh \beta_{I}\left(w_{I}-x\right)}{\left(\sinh ^{2} \beta_{I} w_{I}\right)}\right]+$

$+\frac{v}{2 D_{I} \beta_{I}} \frac{\partial p\left(w_{I}, y\right)}{\partial y}\left[x \frac{\cosh \beta_{I} x}{\sinh \beta_{I} w_{I}}-w_{I} \frac{\cosh \beta_{I} w_{I} \sinh \beta_{I} x}{\left(\sinh ^{2} \beta_{I} w_{I}\right)}\right]$.

Here we have neglected terms which are proportional to $v^{2}$ and the other higher degrees of $v$. Now we can calculate the current densities:

$$
\begin{aligned}
& j_{I}(y)=-e D_{I} \partial p /\left.\partial x\right|_{x=0}=j_{11} e^{\psi_{I}}-j_{12} e^{2\left(\psi_{I}-\psi_{I I}\right)}+ \\
& +v \frac{\partial}{\partial y}\left(\lambda_{11} e^{\psi_{I}}-\lambda_{12} e^{2\left(\psi_{I}-\psi_{I I}\right)}\right) \\
& j_{2}^{\prime}(y)=-e D_{I} \partial p /\left.\partial x\right|_{x=w_{I}}=j_{21} e^{\psi_{I}}-j_{22}^{\prime} e^{2\left(\psi_{I}-\psi_{I I}\right)}+ \\
& +v \frac{\partial}{\partial y}\left(\lambda_{21} e^{\psi_{I}}-\lambda_{22}^{\prime} e^{2\left(\psi_{I}-\psi_{I I}\right)}\right),
\end{aligned}
$$

where $j_{i j}, j_{22}^{\prime}$ are the expressions from (9), (10) and

$$
\begin{aligned}
& \lambda_{11}=\frac{e p_{01}}{2 \beta_{I}} \cdot \frac{\cosh z_{I} \sinh z_{I}-z_{I}}{\sinh ^{2} z_{I}}, \quad \lambda_{22}^{\prime}=\lambda_{11} \frac{p_{02}}{p_{01}}, \\
& \lambda_{21}=-\frac{e p_{01}}{2 \beta_{I}} \cdot \frac{z_{I} \cosh z_{I}-\sinh z_{I}}{\sinh ^{2} z_{I}}, \quad \lambda_{12}=\lambda_{21} \frac{p_{02}}{p_{01}} .
\end{aligned}
$$

Then we can derive an expression, which is similar to Eq.(43), for distribution of electrons, $n(x, y)$, in base II with high injection level in it, and calculate current densities:

$$
\begin{aligned}
& j_{2}^{\prime \prime}=j_{2} \frac{b}{1+b}+\left.e D_{I I} \frac{\partial n}{\partial x}\right|_{x=w_{I}+0,}, \\
& j_{2}=j_{3}=\left.e(1+b) D_{I I} \frac{\partial n}{\partial x}\right|_{x=w_{I}+w_{I I}},
\end{aligned}
$$

As a result we can write down:

$$
\begin{aligned}
& j_{2}=j_{3}=(1+b) \times \\
& \times\left[j_{33} e^{\psi-\psi_{I I}}-j_{33} e^{\psi_{I}-\psi_{I I}}+v \frac{\partial}{\partial y}\left(\lambda_{33} e^{\psi-\psi_{I I}}-\lambda_{32} e^{\psi_{I}-\psi_{I I}}\right)\right] \\
& j_{2}^{\prime \prime}=\left(b j_{33}+j_{23}\right) e^{\psi-\psi_{I I}}-\left(b j_{32}+j_{22}^{\prime \prime}\right) e^{\psi_{I}-\psi_{I I}}+ \\
& \left.+v \frac{\partial}{\partial y}\left[\left(b \lambda_{33}+\lambda_{23}\right) e^{\psi-\psi_{I I}}-\left(b \lambda_{32}+\lambda_{22}^{\prime \prime}\right) e^{\psi_{I}-\psi_{I I}}\right)\right]
\end{aligned}
$$

where

$$
\begin{array}{ll}
\lambda_{33}=\frac{e n_{03}}{2 \beta_{I I}} \cdot \frac{\cosh z_{I I} \sinh z_{I I}-z_{I I}}{\sinh ^{2} z_{I I}}, & \lambda_{22}^{\prime \prime}=\lambda_{33} \frac{n_{02}}{n_{03}}, \\
\lambda_{32}=-\frac{e n_{02}}{2 \beta_{I I}} \cdot \frac{z_{I I} \cosh z_{I I}-\sinh z_{I I}}{\sinh ^{2} z_{I I}}, & \lambda_{23}=\lambda_{32} \frac{n_{03}}{n_{02}} .
\end{array}
$$

Taking into account inequality (35) and the equation $j_{2}=j_{2}^{\prime}+j_{2}^{\prime \prime}$, we obtain for uniformly doped base I:

$$
\begin{aligned}
& e^{\psi_{I}-\psi_{I I}} \cong \\
& \cong \frac{j_{21} e^{\psi_{I}}+v(\partial / \partial y)\left[\lambda_{21} e^{\psi_{I}}-\left(\lambda_{22}^{\prime \prime}-\lambda_{32}\right)\left(e^{\psi_{I}-\psi_{I I}}+e^{\psi-\psi_{I I}}\right)\right]}{\left(1-\alpha_{I I}\right)\left(\lambda_{22}^{\prime \prime}+\lambda_{32} e^{\psi-\psi_{I}}\right)}
\end{aligned}
$$

Using Eqs.(44), (50) and (54), we derive the equation which is similar to eq.(36) but for nonstationary case:

$\frac{k T}{e} \sigma_{I} \frac{d^{2} \chi}{d y^{2}}=R(\chi)+v \cdot e^{\psi_{I}(\infty)}\left[\frac{d}{d y} S_{I}(\chi)+\right.$

$\left.+\frac{\gamma e^{\chi} / A-\delta}{1+e^{\chi} / A} \frac{d}{d y} S_{I I}(\chi)\right]$

Equation (55) differ from Eq.(36) by the proportional to $v$ term on the RHS of the equation, where

$S_{I}(\chi)=e^{\chi}\left(\lambda_{11}+\frac{1+b}{1-\alpha_{11}} \cdot \frac{j_{21}}{j_{33}} \cdot \frac{\lambda_{32} e^{\chi} / A-\lambda_{33}}{1+e^{\chi} / A}\right)$

$S_{I I}(\chi)=e^{\chi}\left(\lambda_{21}+\frac{j_{21}}{j_{33}} \cdot \frac{\lambda_{32}-\lambda_{22}^{\prime \prime}}{1-\alpha_{I I}}\right)$,

and $\chi=\psi_{I}-\psi_{I}(\infty)$,

$\gamma=(1+b) \alpha_{I I} /\left(1-\alpha_{I I}\right), \delta=(1+b) /\left(1-\alpha_{I I}\right)$.

We emphasize that Eq.(55) is derived under the several conditions. First, the velocity is small, i.e. we restrict our consideration by the linear on $\mathrm{u}$ terms. Second, the conditions Eq.(35) and $j<<l_{c} r^{2}$ are met (i.e. the strong inequalities (37) and (38) are satisfied). To solve eq.(50) we can exploit the theory for nonlinear stationary waves [17].

The deviation of the gate current from its equilibrium value, $\delta J_{g}=J_{g}-J_{g 0}$, under the constant current density, $\mathrm{j}$, results in the motion of the ON/OFF-junction. The velocity $v$ is equal to

$v=\left[J_{g}^{2}-J_{g 0}^{2}(j)\right] \times$

$\times\left[2 \sigma_{I} \frac{k \mathrm{~T}}{e} e^{\psi_{I}(\infty)} \int_{-\infty}^{0} d \chi\left(\frac{d}{d y} S_{I}+\frac{\gamma e^{\chi} / A-\delta}{1+e^{\chi} / A} \frac{d}{d y} S_{I I}\right)\right]^{-1}$. 


\section{Z. S. Gribnikov et al.: Switching waves in asymmetric thyristor-like structures...}

To calculate the integral we use the dependence $d \xi / d y=$ $=f(\xi)$ from the stationary solution:

$\sigma_{I} \frac{k T}{e} \frac{d \chi}{d y}=\Phi\left(e^{\chi}\right) J_{g 0}(j)$

where

$$
\Phi(z)=\left(\frac{\ln [(1+A) /(z+A)]-(1-z) /(1+A)}{\ln \left(1+A^{-1}\right)-(1+A)^{-1}}\right)^{1 / 2},
$$

Using Eqs.(58) and (59) we can write down the formula for the velocity of the ON/OFF-junction:

$v=\frac{J_{g}^{2}-J_{g 0}^{2}(j)}{2 J_{g 0} \cdot \tau \cdot j}$

Where

$$
\begin{aligned}
& \tau=\frac{1}{j_{11}} \cdot \int_{0}^{1} d z \Phi(z)\left\lfloor\Lambda_{0}+\Lambda_{1}(1+z / A)^{-1}+\Lambda_{2}(1+z / A)^{-2}\right\rfloor, \\
& \Lambda_{0}=\lambda_{11}+\frac{\alpha_{11}(1+b)}{1-\alpha_{I I}} \lambda_{21}+\frac{\alpha_{I}(1+b) j_{11}}{\left(1-\alpha_{I I}\right)^{2} j_{33}}\left(\lambda_{32}-\alpha_{I I} \lambda_{22}^{\prime \prime}\right),
\end{aligned}
$$

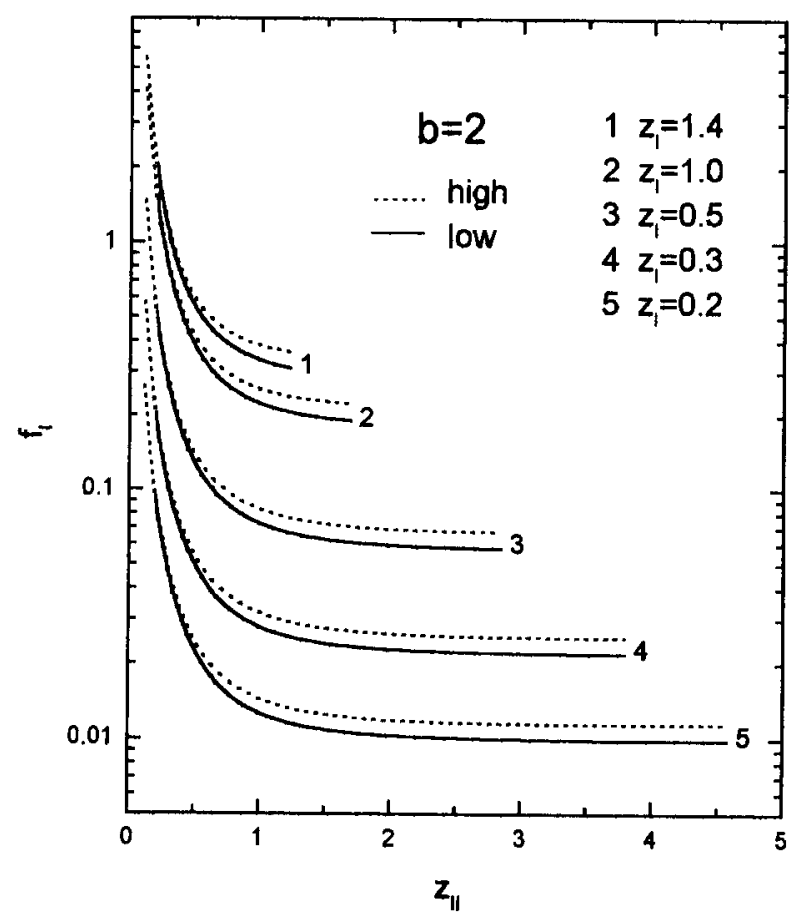

$\Lambda_{1}=-(1+b) \frac{1+\alpha_{I I}}{1-\alpha_{I I}}\left(\lambda_{21}+\alpha_{I} \frac{j_{11}\left(\lambda_{32}-\lambda_{22}^{\prime \prime}\right)}{j_{33}\left(1-\alpha_{I I}\right)}\right)$

$\Lambda_{2}=-\alpha_{I} \frac{1+b}{1-\alpha_{I I}} \cdot \frac{j_{11}}{j_{33}}\left(\lambda_{32}+\lambda_{33}\right)$.

For small deviations of the gate current from the equilibrium value $\left(\delta J_{g}=J_{g}-J_{g 0}(j)\right)$, Eq.(60) can be written in the form:

$v=\frac{\delta J_{g}}{\tau \cdot j}$

The values of $\tau$ and $I_{1}$ depend on geometry and material properties of both bases.

The condition $A>0$ which is equivalent to inequality (31), provides the existence of the ON-state with low voltage across the structure and three forward-biased pnjunctions. The analogous condition for low injection level in both bases [1] does not include the multiplier $b+1$ beside $\alpha_{I}$. That is why this condition is met for wider range of $\alpha_{I, I I}$ for high injection level in base II than for low injection level there. For structures with $n$-doped base I, the inequality $b>1$ (or even $b>1$ for numerous semiconductor materials) is satisfied. This means that condition (31) is met for quite long bases I and II. (For example, just condition $\alpha_{I}>(1+b)^{-1}$ should be met for $\alpha_{I I}=0$.) We have to note, however, that the longer base II is, the higher current density is required to get high injection level over

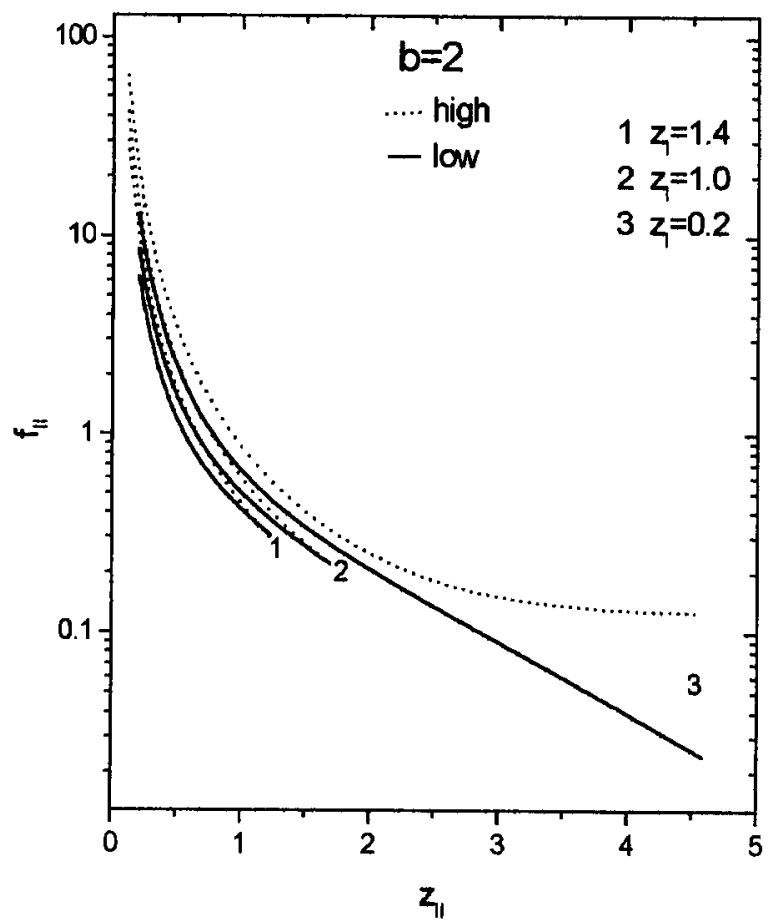

Fig. 3. The dependences of two terms of Eq.(63), $f_{I}$ and $f_{I I}$ for high (dotted lines) and low (solid lines) injection level in base II, on $z_{I I}$ for given values of $z_{I} ; b=\mu_{n} / \mu_{p}=2$. 
Z. S. Gribnikov et al.: Switching waves in asymmetric thyristor-like structures...
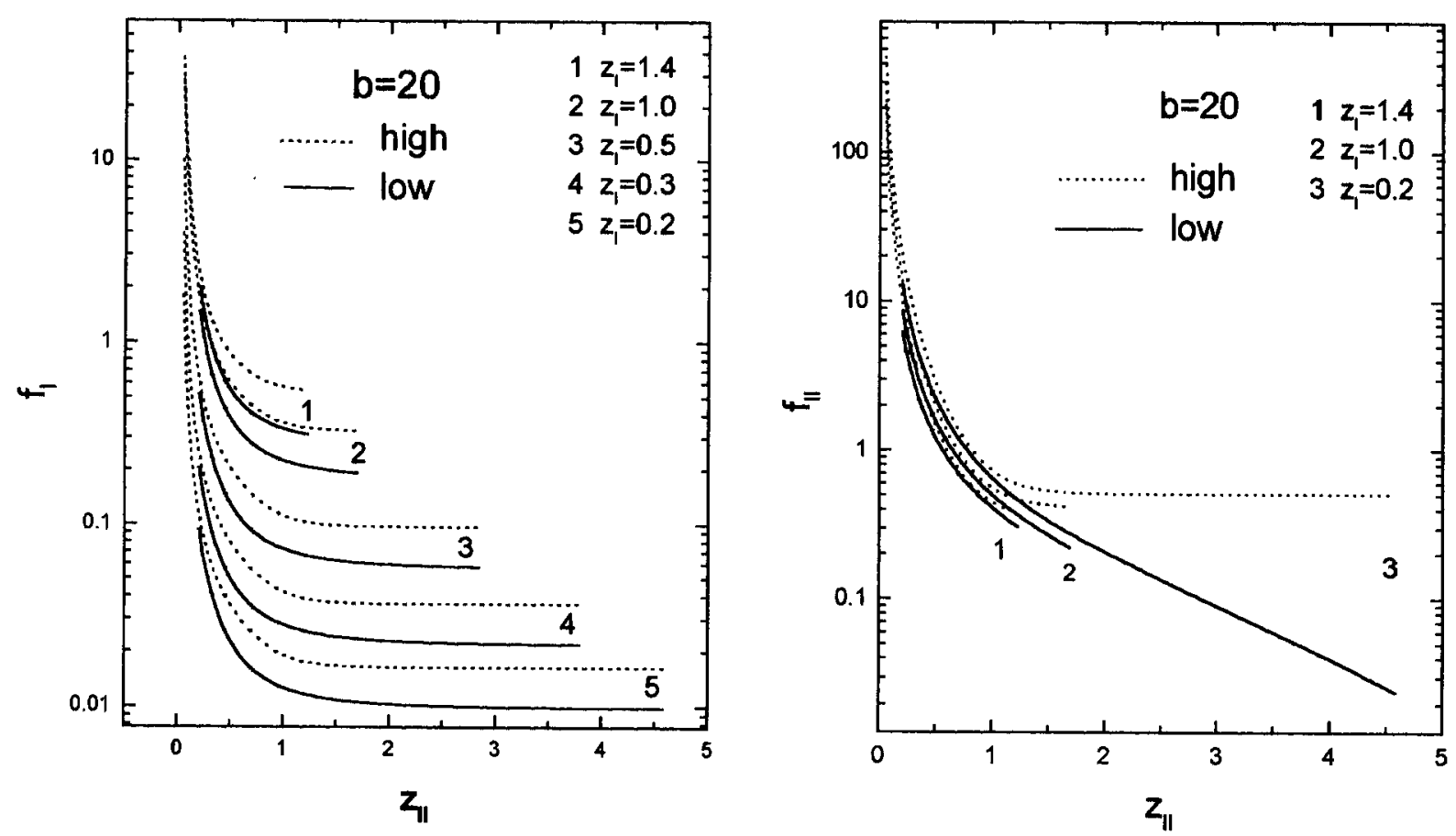

Fig. 4. The same as fig. 3 for $b=\mu_{n} / \mu_{p}=20$.
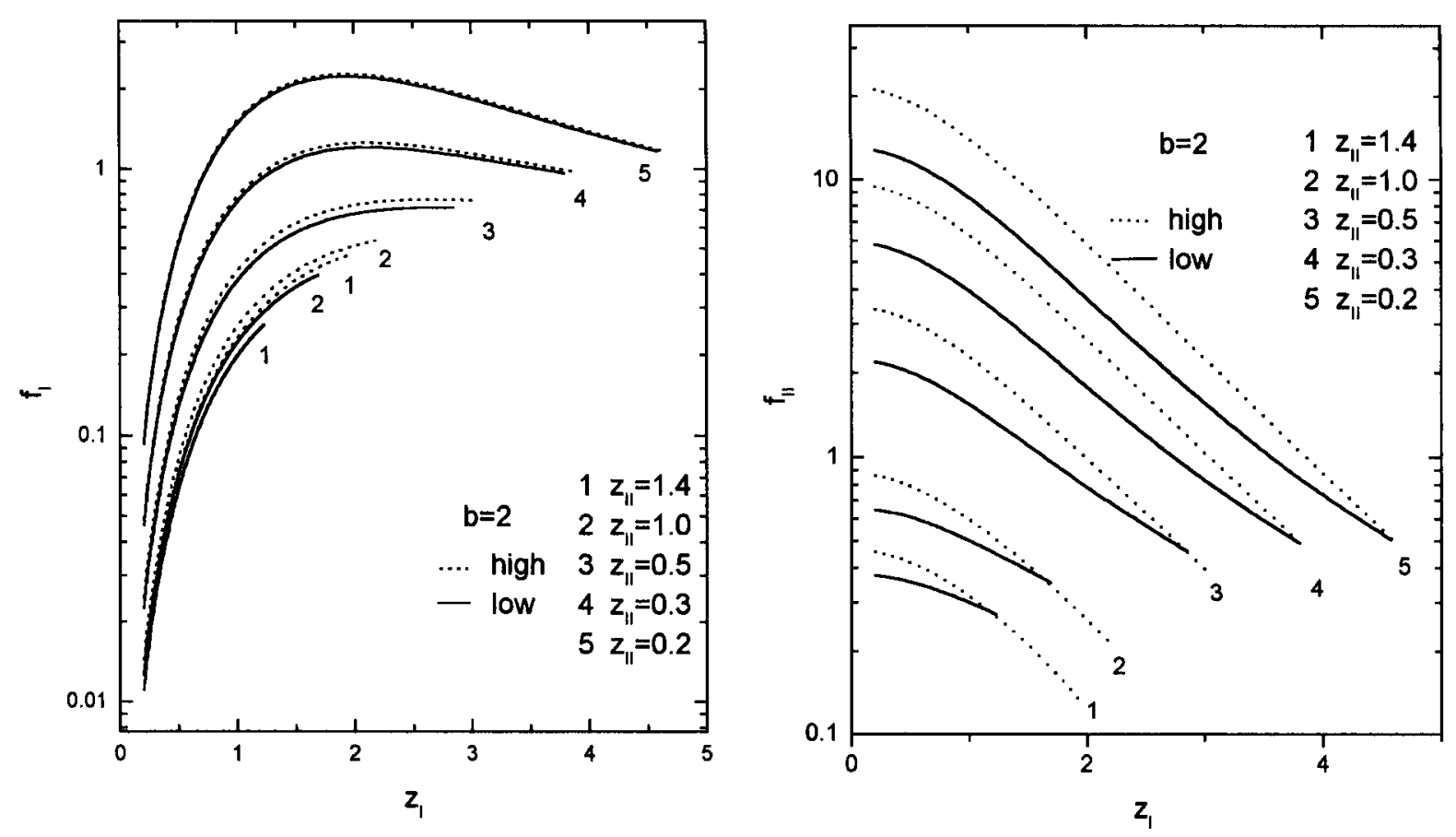

Fig.5. The dependences of two terms of Eq.(63), $f_{I}$ and $f_{I I}$ for high (dotted lines) and low (solid lines) injection level in base II, on $z_{I}$ for given values of $z_{\Pi I} ; b=\mu_{n} / \mu_{p}=2$. 


\section{Z. S. Gribnikov et al.: Switching waves in asymmetric thyristor-like structures...}
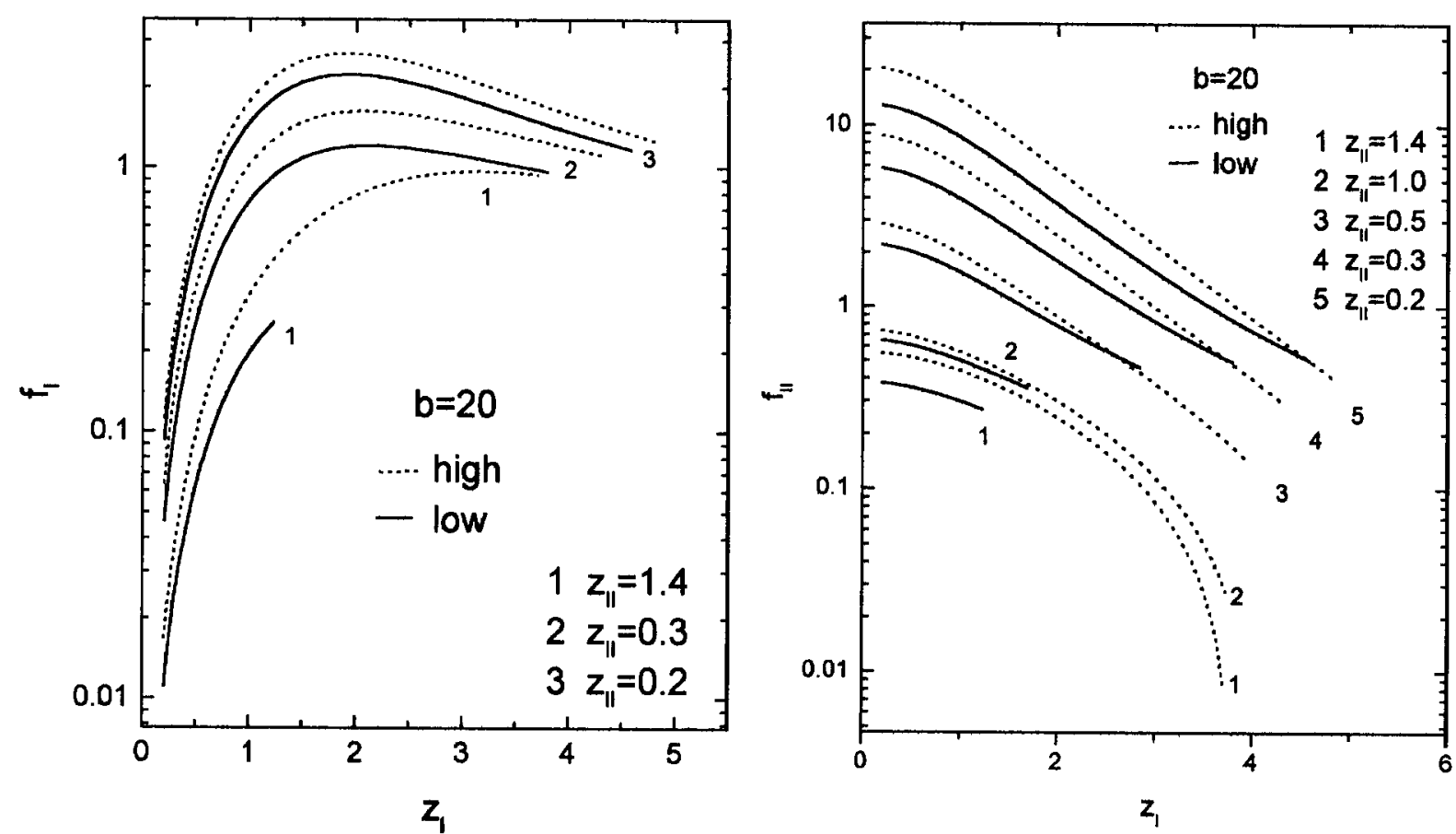

Fig. 6. The same as fig. 5 for $b=\mu_{n} / \mu_{p}=20$.

all length of base II, and the transition into the ON-state occurs at quite high current density $j$. Besides, if the length of base II exceeds 3-4 diffusion lengths, the voltage across the base would become high enough to be taken into account with the voltages across $p n$-junctions.

For uniformly doped bases

$$
\tau=\tau_{I} f_{I}\left(z_{I}, z_{I I}\right)+\tau_{I I} f_{I I}\left(z_{I}, z_{I I}\right),
$$

The dependencies $f_{I}\left(z_{I}, z_{I I}\right)$ and $f_{I I}\left(z_{I}, z_{I I}\right)$ are depicted in fig. 3-6. Each figure contains two branches of curves: solid lines show the dependencies for low injection level in base II; dotted lines show the dependencies for high injection level in base II for the same dimension lengths $w_{I I}$ of base II. The inverse diffusion lengths for high and low injection levels in base II, $\beta_{I I}=\left(D_{I I} \tau_{I I}\right)^{1 / 2}$, are different. For low injection level, $D_{I I}$ is the diffusion coefficient of minority carriers - electrons. For high injection level, $D_{I I}$ is the bipolar diffusion coefficient, $D_{I I}=2 D_{p} D_{n} /\left(D_{p}+D_{n}\right), \quad b=$ $=D_{n} / D_{p}$. Here the values of $D_{p, n}$ being the diffusion coefficients of electrons and holes. In case of low injection level, $D_{I, I I}$ are just the diffusion coefficients of electrons and holes, respectively. Therefore, for the same dimension length $\mathrm{w}_{\mathrm{II}}$, the dimensionless length for low level, $z_{I I}^{(l)}$, and the dimensionless length for high level, $z_{I I}^{(h)}$ differ:

$z_{I I}^{(h)}=z_{I I}^{(l)} \sqrt{(1+b) / 2}$.

In figs. 3-6 the notation $z_{I I}$ refers to low injection level $\left(z_{I I}=z_{I I}^{(l)}\right)$ for the sake of convenience, because $z_{I I}^{(l)}$ does not depend on the value of $b$.
From figs. 3-6, one can see that the growth of injection level in base II does not change the form of the dependencies $\tau\left(w_{I}, w_{I I}\right)$. The growth of injection level results in increasing of $f_{I}, f_{I I}$ for the range of parameters where the open state of TLS is possible for low injection level (i.e. condition $A^{(l)}>0$ is met). It is worth noting the following features of the dependencies $f_{I I I}\left(z_{I I I}\right)$. The functions $f_{I I I}$ diverge with decreasing of $w_{I I}$ up to 0 and decrease with increasing $w_{I I}$. For $w_{I I} \rightarrow \infty$ for low injection level $f_{I I}$ decreases exponentially and goes very close to 0 while for high injection level $f_{I I}$ is saturated for large $w_{I I}$. Therefore the minimum possible value of $f_{I I}$ is much higher for high injection level than for low injection level. With decreasing $w_{I}$, the value of $f_{I}$ goes to 0 while the value of $f_{I I}$ increases slightly. A decrease in the value of $f_{I I}$ with increasing $w_{I}$ is probably caused by failure of the $P^{+}$emitter influence on base II.

\section{Discussion and Conclusion}

In presented paper the problem of the switching wave in an asymmetric TLS with high injection level in ungated base II is discussed; the results are compared with analogous results for a TLS with low injection level in both bases [9]. The transition to the high injection level results in re-definition of the parameters and several restricting inequalities. The field of application of the presented approach extends greatly, because the regime of the TLS with high injection level in lightly doped ungated base II is the typical regime of operation for real 


\section{Z. S. Gribnikov et al.: Switching waves in asymmetric thyristor-like structures...}

TLSs. It is partially due to the fact that the criterion of the ON-state existence can be met for much wider range of parameters in case of high injection level in base II than in case of low injection level there. Especially it is related to structures with a high value of $b=\mu_{n} / \mu_{p}$. Formulae (60) and (62), now being valid for wider range of parameters and regimes, allow us to describe a nonstationary behavior of a finite gate controlled (or gate modulated) TLS.

Using the presented approach and calculations, we can point to several ways to increase the speed of operation of a TLS.

1. Base I should be $n$-doped. Besides, it should be as thin as possible. But base I still has to provide high inplain conductivity which is proportional to $w_{I}$.

2. A length of base II should be of the order of 1-2 diffusion length of minority carriers in this base. This range of $w_{I I}$ provides small (almost minimum possible) values of $f_{I}$ and $f_{I I}$. The lifetime of carriers in base II should be chosen as small as possible. For this purpose the base has to be doped by effective recombination centers. It is the base that should operate as an active region in a light-emitting regime. A decrease in the values of $\tau_{I I}$ and $w_{I I}$ is to be restricted by a given value of the breakover voltage (for a thyristor regime of operation) and a maximum value of the blocking gate voltage applied for squeezing. It is also necessary to avoid the pinchthrough of base II and the growth of an ineffective transistor current (from the cathode to the gate) through this base.

3. Probably, it is better to use modulation doped structures instead of uniformly doped ungated base considered here. This structure which can avoid the pinchthrough, should consist of active layers with low effective lifetime, $\tau_{I I}$, and blocking low recombination layers. As an active region, one can use a layer with a quantum well (or quantum wells). In this work, only the calculations for uniformly doped bases I and II are presented in detail while modulation doped (layered) bases and bases with heterostructure junctions or quantum wells can be used for real light-emitting devices. To describe the modulation doped structure we just have to derive new expressions for $j_{i, j}, j_{22}^{\prime \prime}, j_{i, j}$, and for $J_{g 0}(j)$ and $\tau$.

It is worth to emphasize that we consider only asymmetric TLSs, where in-plain conductivities of bases differ greatly. If the currents through both bases are of the same order, or if both bases are gated (i.e. both bases control the current through a TLS), the calculation would be much more complicated. For these cases, the stationary wave approach which uses just one parameter, wave velocity $v$, may be inappropriate. However, the approach proposed here is valid for all the cases when the gate current flows mainly through the gated base and may be successfully used for real asymmetric TLSs.

\section{Acknowledgements}

This work was supported by the National Science Foundation of the USA. One of us (Z. S. Gribnikov) thanks the Ukrainian Foundation of Fundamental Researches for a partial support. We also thankful to the editorial board of the "Semiconductor Physics, Quantum Electronics \& Optoelectronics» for the invitation to submit our paper to the first issue of this new journal.

\section{Reference}

1. N. Vagidov, Z. Gribnikov, A. Korshak, V. Mitin, Semiconductors, 1995, 29, 1021.

2. Z. Gribnikov, N. Vagidov, A. Korshak, V. Mitin, SolidSt. Electron., 1996, 39, 915.

3. A. Blicher, Thyristor Physics, Springer-Verlag (1976).

4. Z. Gribnikov, V. Mitin, A. Rothwarf, Proceed.1993 ISDRS, 1993, 2, 603 .

5. M. Levinstein, Sov.Phys.Tech.Phys., 1981, 26, 720.

6. K. Kasahara, IEEE J. Quantum Electron., 29, 757 (1993).

7. P. Heremans, M. Kuijk, R. Vounckx, G. Borghs, J. Phys. III France, 4, 2391 (1994)

8. P. A. Evaldsson, G. W. Taylor, P. W. Cooke, S. K. Saragood, P. A. Kiely, D. P. Docter, IEEE Photon. Technol. Lett.,5, 634 (1993).

9. Z. Gribnikov, I. Gordion, V. Mitin, Solid-St.Electron., (submitted).

10. K. Kasahara, J. Tashiro, N. Hamao, M. Suigimoto, T. Yanase, Appl. Phys. Lett., 52, 679 (1998).

11. J.Tashiro, K.Kasahara, N.Hamao, M.Suigimoto, T.Yanase, Japan J. Appl. Phys.,26, n6, L1014 (1987).

12. G. W. Taylor, R. S. Mand, J. G. Simmons, A. Y. Cho, Appl. Phys. Lett., 50, 338 (1987).

13. D. L. Crawford, G. W. Taylor, J. G. Simmons, Appl. Phys. Lett., 52, 863 (1988).

14. D. L. Crawford, G. W. Taylor, P. Cooke, T. Y. Chang, B. Tell, J. G. Simmons, Appl. Phys. Lett., 53, 1797 (1988)

15. G. W. Taylor, D. L. Crawford, J. G. Simmons, Appl. Phys. Lett., 54, 543 (1989).

16. P. R. Claisse, G. W. Taylor, D. P. Docter, P. W. Cooke, IEEE Transact. Electron Devices,39, 2523 (1992).

17. A. Vl. Gurevich, R. G. Mints. Sov.Phys.Usp., 27, 19 (1984).

\section{ХВИЛІ ПЕРЕКЛЮЧЕННЯ В АСИМЕТРИЧНИХ ТИРИСТОРО ПОДІБНИХ СТРУКТУРАХ В РЕЖИМІ ВИКЛЮЧЕННЯ РОЗІМКНУТОГО ЗАТВОРУ}

\section{3. С. Грибніков \\ Інститут фізики напівпровідників НАН Украӥни}

И. М. Гордіон, В. В. Мімін

Детройтський держсавний університет ім. А. Вейна, США

Резюме. Розглянуто стаціонарну хвилю переключення в кінцевій тиристоро подібній структрурі (ТПС). Ця хвиля ініційована контролюючим струмом затвору $I_{g}$, який відрізняється від певного рівноважного струму $I_{g 0}(j)$, який забезпечує положення нейтральної рівноваги (трансляційно інваріантної) перехідного шару між запертою та відкритою областями для даної густини струму $j$ у відкритій області. Виведено залежність швидкості хвилі $v\left(I_{g}, j\right)$ від струму 


\section{Z. S. Gribnikov et al.: Switching waves in asymmetric thyristor-like structures...}

затвору $I_{g}$ та густини струму $j$. Ми маємо справу із структурою, в якій провідність запертої бази І набагато выща, ніж провідність незапертої бази II. Розглянутий рівень інжекції є низким для бази I та високим для бази II. Показано, що швидкість хвилі переключення (тобто швидкість перехідного процесу в ТПС) визначається головним чином параметрами бази II. Продемонстровано також, що висока швидкість спрацювання може бути досягнута в структурі 3 помірно довгою базою II (довжина бази повинна перевищувати 1-2 біполярних дифузійних довжин) та малим часом життя носіїв в цій базі.

\section{ВОЛНЫ ПЕРЕКЛЮЧЕНИЯ В АССИМЕТРИЧНЫХ ТИРИСТОРО ПОДОБНЫХ СТРУКТУРАХ В РЕЖИМЕ ВЫКЛЮЧЕНИЯ РАЗОМКНУТОГО ЗАТВОРА}

\section{3. С. Грибников}

Институт физики полупроводников НАН Украины

И. М. Гордион, В. В. Митин

Детройтский государственный университет им. А. Вейна, США

Резюме. Рассмотрена стационарная волна переключения в конечной тиристоро подобной структруре (ТПС). Эта волна инициирована контролирующим током затвора $I_{g}$, который отличается от определенного равновесного тока $I_{g 0}(j)$, обеспечивающего положение нейтрального равновесия (трансляционно инвариантного) переходного слоя между запертой и открытой областями для данной плотности тока $j$ в открытой области. Выведена зависимость скорости волны $v\left(I_{g}, j\right)$ от тока затвора $I_{g}$ и плотности тока $j$. Мы имеем дело со структурой, в которой проводимость запертой базы I много выше, чем проводимость незапертой базы II. Рассматриваемый уровень инжекции является низким для базы I и высоким для базы II. Показано, что скорость волны переключения (т.е. скорость переходного процесса в ТПС) определяется главным образом параметрами базы II. Продемонстрировано также, что высокая скорость срабатывания может быть достигнута в структуре с умеренно длинной базой II (длина базы должна превышать 1-2 биполярных диффузионных длины) и малым временем жизни носителей в этой базе. 